\title{
Leading Trends in Marketing Research: a Case of Big Data
}

\author{
Veronika Chernova \\ Marketing Department \\ People Friendship University of Russia \\ Miklukho-Maklaya str. 6, 117198 Moscow \\ Institute Marketing \\ State University of Management \\ Ryazansky Prospekt 99, Russia, 109542 Moscow \\ Russian Federation \\ e-mail: veronika.urievna@mail.ru \\ Vasily Starostin \\ Institute Marketing \\ State University of Management \\ Ryazansky Prospekt 99, Russia, 109542 Moscow \\ Russian Federation \\ e-mail: write2starostin@gmail.com
}

\begin{abstract}
This paper focuses on the leading trends in marketing research in the digitalised and globalised world. Specifically, it tackles the issue of Big Data and explores the ways how it is used in collecting, processing, and analysing the data of consumers and potential customers.

We show that over the last several years, Big Data has found its way into marketing strategies of large companies and helps them to target and get a way more customers that previously using traditional methods. The popularity of online content and social networks make this task even easier. Thence, it is clear that marketing managers want to know how they can monetize Big Data.

In addition, we focus on the way the Big Data is collected and processed. From fitness trackers to online behaviour or social networks, fora, blogs, but also online shops and auctions, Big Data can provide valuable insights for marketing specialists. We use several examples of Big Data in marketing from several countries, regions, as well as areas of business to prove our points.

Our results confirm that Big Data became an important part of marketing strategies and marketing research and there is hardly anything one can do to defy this. Rather than opposing the Big Data in the daily use, large companies should learn how to use it properly for increasing the customer satisfaction and providing customer support in all areas of business.
\end{abstract}

\section{Introduction}

As our world is becoming smaller due to the digitalisation and globalisation processes, the online participation increases. With all the opportunities to access virtually unlimited loads of information, today's consumers have a greater impact on products and brands and have greater control over the commercial market (Zielińska 2016; Velilla 2018; Dhadhal 2018). In addition, companies need to be aware that digital technology is becoming an effective but very dangerous tool for influencing and changing consumer behaviour (Chiabai et al. 2014; Ko et al. 2013; Rovai 2015; or Chernova et al. 2019). In a world where new technologies are constantly emerging, companies that focus on consumer needs are in a position to win (Strielkowski 2019). The key is to interest consumers personally on their brand and how the consumer perceives the brand.

As we all know, consumer behavior today is affected by various aspects (Davydov 2007). As technology advances, consumer behavior in the market has changed dramatically. Because of the technological implications that influence consumer behavior, most corporate leaders face the endless challenge of meeting consumer expectations. Structural changes in the supply of products and services are the result of the impact of technological progress on society, but also of the evolution of the factors that compose demand. The behavior of all, who can be considered as customers, industrial companies, service providers, state and non-governmental institutions as well as individual consumers, shows spectacular changes as a result of the development of the value system and the possibilities to change the lifestyle.

Moreover, it should be noted that business organizations have changed their ethical and social responsibility (Spence 2016). The results therefore provide only limited insight into customer attitudes to loyalty and behavioral intentions regarding the use of self-service technology systems. Therefore, additional investigations should be carried out to closely monitor the behavior of the customer in some other regions. 
Because this study was purely quantitative in nature, there are certain limitations to survey-based data collection (see e.g. Minaev et al. 2018). Therefore, further research should be conducted using a variety of methodological approaches. Here is where mixed methodology and qualitative approaches might come quite handy. In addition, some other variables, i.e. the company image of the service provider used in the current model as a moderation or mediator variable for future research purposes. Product development teams are now faced with the new challenge of interpreting and processing the vast amounts of customer information they now collect. Tracking online customer behavior has created large amounts of data that must be gathered and analysed (Khare et al. 2012).

However, when it comes to understanding real-world behavior in offline mode, researchers typically use contextual methods such as ethnographic studies and user interviews (Rinaldo and Guhin 2019). In order to gain insights into consumer behavior, researchers use popular market research methods such as surveys, in-depth interviews, and focus groups. Increasingly, researchers are turning to newer methods and technologies to gain a deeper understanding of why consumers behave in a certain way. In addition, researchers often turn to separate disciplines to gain insights that allow the study of consumer behavior. For example, behavioral economics provides new insights into specific aspects of consumer behaviour (Chiabai et al. 2014; Abrham and Wang 2017). However, all these methods represent the so-called "soft" methods and can only provide limited information and insights. This is why some more profound and comprehensive sources of data is needed. Here is where Big Data can come handy providing a very detailed and accurate account of the consumer preferences and characteristics.

All in all, a thorough understanding of consumers and their customers creates invaluable insight and proves to be essential to achieving the core and crucial business goals. Such insights also occur when one engages with them online or elsewhere to gain their impartial feedback on a specific area of the customer experience so she or he can respond.

Today, with the possibility to obtain advanced analytics, stronger customer contact points and other behavioral support, insurers can understand customer attitudes and behaviors faster and better. As multicultural consumers have accounted for most of our population growth in recent years, it is important to know how they differ in their attitudes and behaviors in relation to insurance and financial issues in general.

One of the good examples of that is the Internet streaming giant Netfix. By using customer data and analytics, Netflix can accurately determine the amount of usage activity that a single customer needs each month to earn enough value to continue subscribing. With this realization, Netflix knew they needed to find more ways to engage users and consume more content each month. They have launched a number of initiatives to improve their recommendation algorithms and to find new ways and channels to provide personalized content recommendations based on user behavior. Netflix also uses customer behavior data to make decisions about what content to produce and license. All of the above also helps them to prevent churn and improve customer acquisition. Other companies such as Buffer, Wistia and Mailchimp also value customer training and ensure that customers get the best possible product experience.

\section{Big Data in marketing research}

The marketing, trade, and operational contribution to analyzing data streams similar to big data can be valuable and diverse. Good capture, good management, simulation, analysis, and use of Big Data data make it possible to uncover hidden relationships, identify new opportunities, refine some offerings, make organizational changes, and make changes in communication (Sharma and Oliviera 2017). In short, the great use of Big Data enhances the company's performance and competitiveness by enabling it to respond faster and better to its customers' needs. Of course, each question must be thought through a variety of other considerations, such as data first, big data analytics, and the cost of marketing research (Serban 2017; Chernova et al. 2017). Retrieving big data takes time, while market research can be limited to a certain amount of time to get the insight you need to make a business decision. The question of whether Big Data will make data from direct market research superfluous continues to trigger major debates in the research industry.

In our opinion, these are the main differences between Big Data and market research. Big Data and market research should always complement each other, not replace them. Properly used, they can be extremely effective in understanding customer behavior. This is why it is important to learn more about the existing leading approaches to integrating market research and Big Data. Market research can help to get that information through a variety of polls to tell the entire story.

Another important step is to switch from what one thinks is Big Data to the real Big Data. Although market research data tends to be smallerin sample size, it is full of information about motivations, perceptions, and context for behavior. By integrating with the larger datasets, one can further expand your big data dataand get information on requirements, opportunities, alignment, and innovation opportunities. Well-accessible information about consumer activities and preferences enables market researchers to develop large amounts of data to gain consumer insights. Indeed, a look at recent market research publications shows that discussions in 
this area have been dominated by a focus on data analysis. In most cases, the insight into what really interests customers is compromised by the quality of the data collected.

Decades before the first mention of big data, companies analyzed the data collectedto gain insights and uncover trends. Basically, the modern big-data analysis systems allow fast and efficient analysis methods. In the meantime, companies can work more cheaply with Big Data analysis software.

In the modern business world and the current technology age, a business can easily capture all the customer data it needs. Basically, only a big data analysis strategy is needed to maximize available data. With an appropriate mechanism for analyzing customer data, a company can derive critical behavioral insights to which it must respond in order to maintain the customer base.

Nowadays, companies are missing out on data mining specialists from Big Data. Some propose to entrust big data internally to a CAO that is directly associated with the management and is capable of collecting and analyzing data both from a technical point of view (in collaboration with computer directors) and marketing (in collaboration with $\mathrm{CAO}$ ) to understand the marketing directors (collaboration). Conversely, if the organization does not use big data specialists directly, the appropriate institutions may position themselves as privileged specialists in the field and offer their expert assessment to both computer directors and marketing directors.

Despite its limitations, one can suggest that the two aspects of Big Data can improve market research. First of all, there is predictive analytics that can append information to survey data, especially in companieswith large customer information warehouses, to increase the segmentation value. In addition, marketing researchers can use data mining to create custom reports or segmentations from such stores. In other words, the data proves the impact, while the research that is linked to it provides the causal foundations.

Finally, it is important to discover several preferred funds from the same customers. Offering smaller quantities of packages and reminding them of the actual benefits of the premium product can be a good and productive strategy. In the above example, Big Data marketing research is the observation of behavioral changes in the market or customer database, followed by recruitment studies to understand what drives this behavior. The bottom line is that integrating multiple data sources and different analytic disciplines delivers superior insight that can be applied immediately to improve business performance.

\section{Tracking Big Data in motion}

Another area of Big Data collection and use is represented by smart fitness trackers that are used to monitore one's motion, heartbeat (pulse), as well as a variety of other characteristics. Fitness trackers are becoming increasingly popular and they provide an endless stream of data of the customers including their physique as well as geographical location and motion.

One of the leaders on the fitness trackers market, Fitbit, has combined sensors, wireless technology, software and services to pioneer the connected health and fitness market. In order to help customers, take full advantage of Fitbit and lead a healthier and more active life, the company uses social media and strong community support, in addition to phone, email and chat customer support, to provide information about totransmit and collect the product usage.

Another example is the Wearable Activity Tracker and the emerging industry that tracks physical and health activities. Some may also detect and monitor heart rate, blood sugar levels and other basic physiological parameters. Most of them measure only a few activities, differ in terms of measurement reliability and physicality, offer only a few interpretive analyzes, pose technicalchallenges to all but the most technically appropriate, and are poorly integrated with other devices, sites, and sources of health data. Because they are a widely used consumer device that keeps many millions of consumers around the world, monitoring sleep and synchronizing with the IoT ecosystem, they are a great example of a discussion of the complexity of the IoT, and we will use it for this purpose. Health Activity Trackers are increasingly providing data not only to you, but also to your social network, your doctor, your hospital and your health insurance. Since Activity Tracker collects different types of data for different functions in different formats, the integration layer is a significant challenge. An important challenge is working with other organizations on data and communication standards and integration issues. The current data scandal surrounding the controversial analytics company cambridge analytica, which has hit as many as 80 million Facebook users to date, highlights some features of fitness tracker apps. For example, users should critically question the sharing of fitness values in social networks. On the other hand, users need to know that Facebook and other companies have accessto health data from the app and share that data with other companies.

The features of fitness trackers usually decide for the customer. If the customer is looking for a tracker that plays a vital role in training, improving yourhealth, weight, or sleep problems, then the data and tracking should be high on her or his list. In terms of data (and also on the user experience), another feature that one might be interested in is feedback or motivation. Some fitness trackers and their apps do a great job of keeping users motivated by competing with other users, offering virtual rewards, or encouraging words. Although fitness 
trackers should not cure or prevent any disease, they can provide valuable insights into one's physical and mental condition. Smartphone compatibility means that our smartphones are probably the most important technical devices for connecting to fitness trackers and transferring the Big Data from them to the marketiers. Therefore, it may be helpful to use fitness trackers that connect to smartphones. In addition, some trackers are equipped with smartphone apps, so one can store all her or his data in one convenient location. Accordingly, the health insurance also subsidizes the purchase of a fitness bracelet or an apple watch pro rata, if they are compatible with the respective apps.

Fortunately, there are many tools that allow app developers to integrate wearables into their health and fitness software. Garmin, Fitbit, Withings and TomTom provide tools to integrate with their products that allow users to track their mobile fitness programs. Google and Apple want to use Google Fit and HealthKit to build ecosystems that serve as hubs for consolidating activity log, health and fitness data. The spread of fitness apps has led to a variety of activity tracking apps. Activity tracking wearables, as well as health and fitness apps, provide great opportunities for developers to encourage people and help them lead healthy lifestyles. The demand for these solutions and the development potential for fitness or health apps is dizzying. Fitness equipment is experiencing strong growth and its activities are getting better every year. Fitness Activity Monitoring began in 2007 when brands such as Fitbit, Jawbone and Nike entered the health and fitness market with activity tracking devices. It was soon followed by Samsung, LG, Pebble, and other companies whose portable devices included activity tracking features. They represent the lowest layer of the Internet of Things (IoT) with the ability to capture an aspect of the physical environment. Local perception is unable to orchestrate a complex process. At this local level of the IoT, such devices as the Activity Tracker is usually connected to one ormore other devices to collect simple actions and data. For example, an activity tracker can usually exchange data with one's laptop or smartphone and convinently transfer data to the producer for further analysis and assessment in the interest of marketing research.

\section{New approaches to online advertising and social networking}

The Chinese technology and Internet company Alibaba is a good place to see where the future of marketing with its leading approaches and techniques will lead ( $\mathrm{Xu}$ et al. 2017). It gives everyone, no matter where you are, an insight into the future of the business. What it does is right at the heart of every economy: retail, advertising, logistics, and supply chain.

China has become the largest production center in the world over the last 40 years, following economic reform and open-door policies (Shangquan 2016). In China, on the one hand, there are many customers, but on the other there is also the world's largest network of supply chains. And then it will be the biggest and one of the largest hypermarkets. Leaders have emerged as new technologies have been applied to new issues such as online advertising, auctions and social networking. The size of the Chinese market and the enormous number of Chinese customers made it an excellent playground and a test site for the Big Data in marketing. It is much easier to develop and test any algorithm when one has almost a billion of test subjects hugry for gadgets and luxury brands. Thence, Alibaba and its followers profited from this comparative avantage even though the basic idea behind Alibaba is not new. In fact, it was very much borrowed from the existing online retailing giant Amazon that served as an inspiration.

The growth of Alibaba group's domestic retail website, Taobao, is driven by the continuous software warning of the retail process. Main brand and family brand architecture are important here. Alibaba, the main brand, gives all the brands in the product family their value, promise and philosophy. The product brand architecture includes the product brand portfolio that was created to give customers a clear value proposition. It is estimated that Alibaba Group increased the number of consumers active on its retail markets to 552 million by the end of December 2017 (Rogers 2018).

In general, it is estimated that shoppers typically spend more than 20 minutes a day using the Taobao app, scanning an average of 19 products and leaving over 20 million reviews or comments (Brennan 2016). In addition, significant revenues are generated from ad revenue from vendors or external companies. From the vendor's point of view, perhaps the most significant difference is that it is free.

Content and social networking have been Tencent's main drivers of revenue since theearly years, but new initiatives are beginning to take root. The need for diversification has become increasingly pronounced recently as Tencentfaces stricter government controls in the gaming sector and intense rivalries from ByteDance, the new darling of advertisers and owners of TikTok and Douyin. Tencent also achieved cloud services revenues for the first time.

Thefore, the advancements in social networking and digital marketing that one can observe in China makes a big impression. One can only wonder whether they can be repeated in some smaller countries where the markets and the numbers of customers are smaller in scope. 


\section{Conclusions}

Overall, one would probably agree that Big Data became an important part of marketing strategies, marketing planning, marketing research, and all advertising and sales processes worldwide. It is easy to see why it is so important nowadays: for consumers it constitutes an easy way how to convey their preferences to the sellers and producers; for producers and sellers it represents an endless source of data on each and every consumer including the personal characteristics, tastes, and lots of very sensitive information.

Nowadays, consumers do not even think about the data they provide online while shopping or registering at various social networks or online communities. Internet shops also collect and process customers' data but very few of us ever think that something might be wrong here. Therefore, large retailers often know about their customers more than they know about themselves.

Recent scandal with the British company Cambridge Analytica demonstrated that micro-targeting is already a reality and it might be used not only in political campaigns, just as Cambridge Analytica did, but also in targeted marketing. Using one's online searches (in Europe, over $90 \%$ of people use Google for their Internet searches), all possible personal data can be collected. Very few of us ever think of our Internet privacy and using some safer online search engines (such as for example Duckduckgo). Of course, this should be changed, and governments worldwide should adapt polices and law protecting consumers from aggressive online marketing that would involve the usage of personal sensitive data.

Big Data are making a new era in marketing research. However, the pace with which it is going is far too fast for the legislative and normative bases to adapt. Thence, customers need to be alert with regart to the fact how their data is collected and used and what it is used for. It is very important to create the boundaries in marketing research than cannot be crossed without solid reasons.

\section{References}

Abrham J, Wang J (2017) Novel trends on using ICTS in the modern tourism industry. Czech Journal of Social Sciences, Business and Economics 6(1):37-43. doi: 10.24984/cjssbe.2017.6.1.5

Brennan T (2016) Consumer engagement driving growth for mobile Taobao. https://www.alizila.com/consumerengagement-driving-growth-on-mobile-taobao. Accessed on 21 November 2019

Chiabai A, Platt S, Strielkowski W (2014) Eliciting users' preferences for cultural heritage and tourism-related eservices: a tale of three European cities. Tourism Economics 20(2):263-277. doi: 10.5367/te.2013.0290

Chernova VY, Zobov AM, Starostin VS, Butkovskaya GV (2017) Sustainable marketing communication strategies of Russian companies under the import substitution policy. Entrepreneurship and Sustainability Issues 5(2):223-230. doi: 10.9770/jesi.2017.5.2(5)

Chernova VYu, Zobov AM, Starostin VS (2019) Dynamics of Digital Inequality in Russia. Media Watch 10(1):225-234. doi: $10.15655 / \mathrm{mw} / 2019 / \mathrm{v} 10 \mathrm{i} 2 / 49622$

Chiabai A, Platt S, Strielkowski W (2014) Eliciting users' preferences for cultural heritage and tourism-related eservices: a tale of three European cities. Tourism Economics 20(2):263-277. doi: 10.5367/te.2013.0290

Davydov D (2007) Interval Perception of Information and Consumer Behavior: Methodological Aspects. Voprosy Ekonomiki 12:60-70. doi: 10.32609/0042-8736-2007-12-60-70

Dhadhal DCH (2018) Brand Preference of Consumers for Selected Brands of FMCG Products - A Study of Rajkot City. RA Journal of Applied Research 04(05). doi: 10.31142/rajar/v4i5.06

Khare A, Dixit S, Chaudhary R, Kochhar P, Mishra S (2012) Customer behavior toward online insurance services in India. Journal of Database Marketing \& Customer Strategy Management 19(2):120-133. doi: $10.1057 / \mathrm{dbm} .2012 .14$

Ko H-T, Chang, C, Chu N-S (2013) An empirical investigation of the consumer demand for digital television application services. Behaviour \& Information Technology 32(4): 397-409. doi: 10.1080/0144929x.2011.608810

Minaev VA, Mazin AV, Zdiruk KB, Poddubnaya EV (2018) Modeling of internal conflicts of automated data collection and data processing systems. Radio industry (Russia) 1:118-123. doi: 10.21778/2413-9599-2018-1118-123 
Rinaldo R, Guhin J (2019) How and Why Interviews Work: Ethnographic Interviews and Meso-level Public Culture. Sociological Methods \& Research, 004912411988247. doi: 10.1177/0049124119882471

Rogers, C (2018) Alibaba's CMO on why marketers cannot 'lag behind reality'. https://www.marketingweek.com/alibaba-marketers-cannot-lag-behind-reality. Accessed on 10 December 2019

Rovai S (2015) Changing patterns of luxury fashion consumer behaviour through digital. Global Fashion Management Conference 3(8):419-420. doi: 10.15444/gfmc2015.03.08.05

Serban R-A (2017) The Impact of Big Data, Sustainability, and Digitalization on Company Performance. Studies in Business and Economics 12(3):181-189. doi: 10.1515/sbe-2017-0045

Shangquan G. China's economic reform, $1^{\text {st }}$ edn. (Springer, New York, 2016), 251 p.

Sharma R, Oliveira S (2017) Community Detection Algorithm for Big Social Networks Using Hybrid Architecture. Big Data Research 10:44-52. doi: 10.1016/j.bdr.2017.10.003

Spence LJ (2016) Small business social responsibility: Expanding core CSR theory. Business \& Society 55(1):23-55

Strielkowski W. Social impacts of smart grids: the future of the smart grids and energy market design, 1 st edn. (Elsevier, London, 2019), 342 p. doi: 10.1177/0007650314523256

Velilla J (2018) The Entrepreneurial Activity Using Gem Data: Evidence for Spain (National and Regional) and for Europe. Journal of Eurasian Economic Dialogue 3(2):18-32

Xu X, Li Q, Peng L, Hsia TL, Huang CJ, Wu JH (2017) The impact of informational incentives and social influence on consumer behavior during Alibaba's online shopping carnival. Computers in Human Behavior 76:245-254. doi: 10.1016/j.chb.2017.07.018

Zielińska A (2016) Information is a market products and information markets. Czech Journal of Social Sciences, Business and Economics 5(4):31-38. doi: 10.24984/cjssbe.2016.5.4.4 